\title{
Stockholm City's Elderly Care and Covid19: Interview with Barbro Karlsson
}

\author{
Charlotta Stern $^{1} \cdot$ Daniel B. Klein ${ }^{2}$ \\ Published online: 19 July 2020 \\ (C) Springer Science+Business Media, LLC, part of Springer Nature 2020
}

\begin{abstract}
Upwards of $70 \%$ of the Covid19 death toll in Sweden has been people in elderly care services (as of mid-May 2020). We summarize the Covid19 tragedy in elderly care in Sweden, particularly in the City of Stockholm. We explain the institutional structure of elderly care administration and service provision. Those who died of Covid19 in Stockholm's nursing homes had a life-remaining median somewhere in the range of 5 to 9 months. Having contextualized the Covid19 problem in City of Stockholm, we present an interview of Barbro Karlsson, who works at the administrative heart of the Stockholm elderly care system. Her institutional knowledge and sentiment offer great insight into the concrete problems and challenges. There are really two sides to the elderly care Covid19 challenge: The vulnerability and frailty of those in nursing homes and the problem of nosocomial infection - that is, infection caused by contact with others involved in the elderly care experience. The problem calls for targeted solutions by those close to the vulnerable individuals.
\end{abstract}

Keywords Covid-19 $\cdot$ Sweden $\cdot$ Stockholm $\cdot$ Elderly care $\cdot$ Nursing homes $\cdot$ Nosocomial

JEL Codes I1 $18 \cdot \mathrm{I} 38 \cdot \mathrm{H} 4$

Nursing homes have been Covid19 hotspots. In many countries upwards of 40,50 , and 60 percent of the deceased taken were in the elderly care system. In Canada it is upwards of 80 percent. This paper is focused on Sweden, where it is upwards of $70 \%$, and more specifically our focus is the City of Stockholm (henceforth "Stockholm city" (stad) as opposed to Stockholm county (län)).

The elderly care tragedy must be studied. Errors must be understood and corrected.

Sweden has not imposed general lockdowns. Its relatively permissive approach has drawn worldwide attention. People ask whether Sweden would have suffered fewer deaths if it had locked down more.

Daniel B. Klein

dklein@gmu.edu

Charlotta Stern

lotta.stern@sociology.su.se

1 Department of Sociology, Stockholm University, SE-106 91 Stockholm, Sweden

2 Mercatus Center, George Mason University, Fairfax, VA 22031, USA
Stockholm is the nation's capital and largest city. The county of Stockholm accounts for $50 \%$ of Sweden's Covid19 deceased (16/5/2020), the Stockholm city accounts for $20 \%$ of Sweden's Covid19 deaths (11/5/2020). Whereas the rate of deaths per million population for the whole of Sweden is 323, it is 697 for Stockholm city (11 May 2020 ${ }^{1}$ ). The city's Covid19 death rate is more than twice that of the country's.

Most Covid19 victims are elderly. In Sweden the percentages of the deceased as of 16 May 2020 are $22 \%$ in their 70 s, $41 \%$ in their $80 \mathrm{~s}$, and $25 \%$ in their $90 \mathrm{~s}$. Altogether that makes $88 \%$ aged 70 or over (see Fig. 1).

Notice in Fig. 1 that the vast majority of the aged 80+ deceased never went to intensive care. Turning now to Fig. 2 , we see that comorbidity is extremely common among the deceased.

The former chief epidemiologist of the Public Health Agency of Sweden Johan Giesecke says bluntly that Sweden has failed in protecting those in elderly care. In some of the

\footnotetext{
${ }^{1}$ The data for Stockholm city comes from: https://platz.se/coronavirus/?city= Stockholm\&lang=en, showing 669 deaths as of May 11, 2020. The data for Sweden comes from: https://www.worldometers.info/coronavirus/\#countries, showing 3256 deaths as of May 11, 2020.
} 
Fig. 1 Age groups of Covid19 deceased in Sweden (May 17, 2020).(Image source)

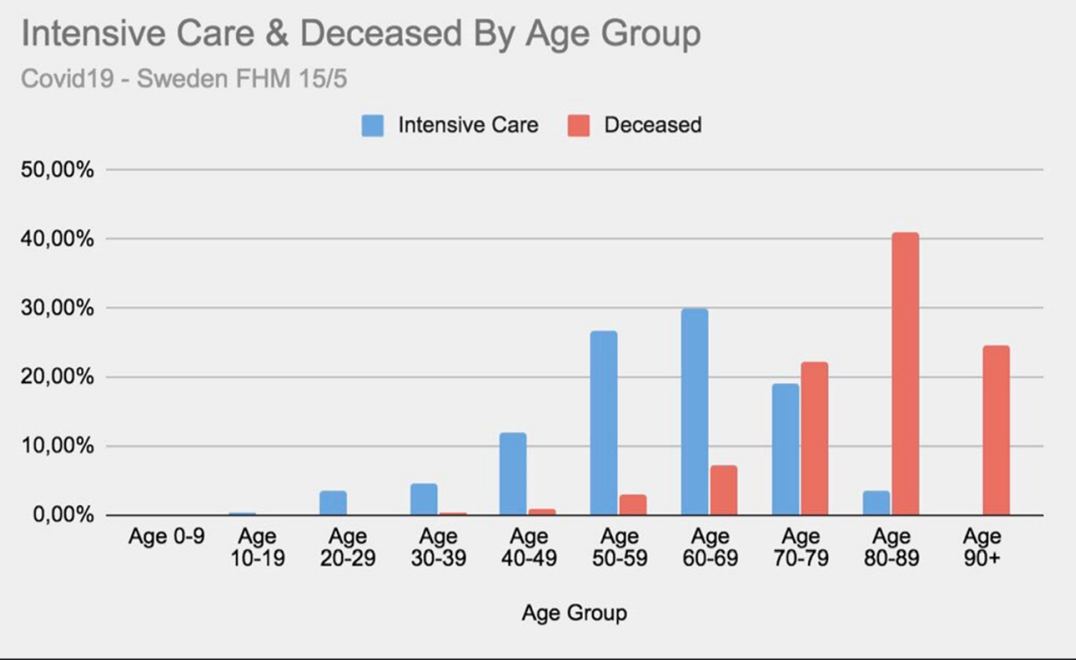

reporting on Sweden the high death toll among the elderly is interpreted as evidence that Sweden's relatively permissive approach to the pandemic has been a failure. But the performance in elderly care and the consequences of the permissive social policy are two different things. According to Anders Tegnell, the current chief epidemiologist, it is hard to see how a lockdown would have prevented the disease from entering the elderly care homes.

The present report is based in part on interviews of a professional who has worked in elderly care for 30 years, and for the past 17 years has worked in Stockholm city's most important elderly-care administrative institution (Äldreförvaltningen). She works in that institution's department that is most significant particularly as concerns the Covid crisis (Stadsövergripande avdelningen). Her name is Barbro Karlsson and her job title is Senior Technical Advisor. The interview was conducted, in Swedish, by Charlotta Stern. They have been good friends ever since meeting at Stockholm University in 1989. The interview material comes at the end of this paper; before that we develop an understanding of elderly-care challenges and of Stockholm city's system. The present article illuminates aspects of the challenge, in a way sympathetic to Karlsson's perspective. Her perspective is a side of the story that has been little heard. The article does not attempt to assess the performance of Stockholm city's elderly care in the face of Covid19. The goal is to illuminate and concretize the events of the Covid19 tragedy in Stockholm's elderly care, to understand the challenges and proper strategies.

To understand Stockholm city's Covid19 death toll, it is crucial to get inside the elderly care system. The system has several arrangements, from nursing homes, to sheltered living homes, to at-home services or "home-care." The home-care and sheltered living options are usually preferred by the elderly who are still able to live on their own (albeit often with extensive home-care). A consequence is that those who
Fig. 2 Deceased with Covid19 and Comorbidities. Source: Socialstyrelsen. (Image source)

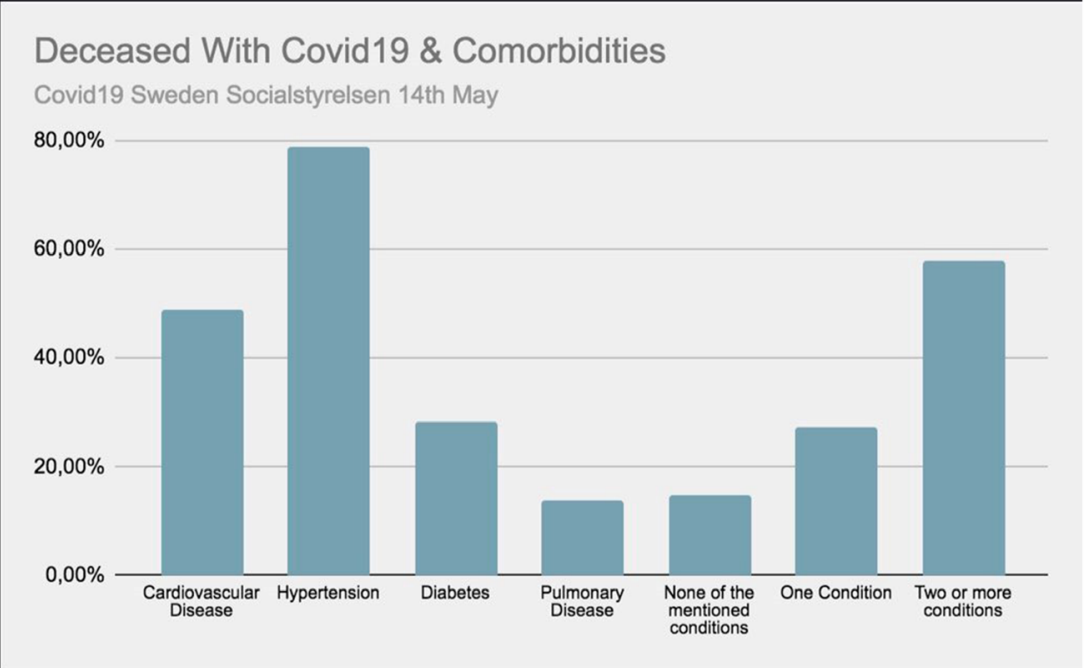


eventually apply and are admitted into nursing homes tend to be exceedingly old and frail. Most of these people have extensive needs both healthwise and livingwise, and do not have long to live, even absent Covid19.

It is important to realize that one must apply for elderly care. Care is provided only to those who are deemed sufficiently in need of the assistance, and assistance is adjusted according to the need. Elderly care is not a benefit freely available to all elderly.

In total, at least ${ }^{2} 79.6 \%$ of the aged 70 or over Covid 19 deaths in Sweden were receiving elderly care services from their municipality $(53 \%$ in nursing homes $+26.6 \%$ home-care; numbers as of 14 May 2020; link). That means that elderlycare users have constituted upwards of $70 \%$ of all Covid 19 deaths in Sweden. ${ }^{3}$ The accusations about failing to protect the vulnerable extends to home-care because it may have been roving staff workers who transmitted Covid19 to the elderly person.

As for the fundamental question of what gets counted as a Covid19 death, the answer is a bit complicated, and we think we understand it. There are two official organizations, each with a separate method, but both work out to roughly the same number because each includes some deaths that the other does not (apparently in roughly equal amounts). ${ }^{4}$

\footnotetext{
${ }^{2}$ We say "at least" because there would also be additional $70+$ deaths (though small in number) of those in elderly-care services other than nursing homes and home-care, but we do not have data for them.

${ }^{3} 70 \%=79.6 \% * 88 \%$.

${ }^{4}$ Most of the data used in this article derives from the National Board of Health and Welfare (Socialstyrelsen), which is the officially designated authority on deaths and their causes. Meanwhile, the Public Health Agency of Sweden (Folkhälsomyndigheten) also reports deaths of people with Covid19 lab-confirmed infection, on a quicker basis, and its numbers are used, for example, at Worldometers (often used in journalistic reporting to make international comparisons). We have reviewed the Board's official Covid19 guidelines issued to doctors about reporting cause of death, the description of how the Board uses that report to arrive at its determination, and a description of the two methods of the two organizations. We have also communicated by email with someone from the Board and with someone from the Agency about the matter. For the Board, the doctor's report largely determines whether the death is reported as a Covid19 death. The form the doctor completes asks him or her to indicate, in part 1 , a primary progression of ailments leading to death, and then, in part 2 , possibly contributory ailments. When the doctor identifies Covid19 as primary, the death clearly is counted as a Covid19 death. But, according to the email we received, when the doctor lists Covid19, not as primary but only as a possibly contributory cause, the death would not be counted as a Covid19 death. (And, of course, the death would not be counted as a Covid19 death if the doctor did not even list it as a possibly contributory cause, even though the patient had Covid19.) For the Agency, a Covid19 death is a death of anyone who was lab-confirmed with Covid19. We have examined Covid19 death counts by the two organizations, and they are roughly equal. The Board includes some deaths that were not lab-confirmed cases of Covid19, while the Agency includes some deaths that the doctor did not deem to have been caused by Covid19 even though the deceased was a labconfirmed case. Apparently the two differentials roughly match and cancel out.
}

\section{Infection and Spread within Elderly Care}

A fine article in City Journal explains the exceptional nursinghome challenges in the United States. Conditions in the United States are not identical to those in Sweden; for example people do not share rooms in Sweden's nursing homes, and medical issues are usually handled at the nursing homes in Sweden, which have medical facilities and professionals on staff. But the difficulty of protecting vulnerable people from infection when those people are in intense need of care and companionship is the heart of the problem worldwide. Chris Pope's renderings about the United States give great insight into the elderly-care corona problem everywhere on the planet (we have removed links within Pope's text):

- "Nursing homes have long been particularly susceptible to infectious diseases, as residents spend most of their days in close contact with others - stuck indoors, eating meals together, sharing rooms, and needing extensive high-touch care from caregivers who move from room to room."

- "Social distancing is hard to practice for residents who need an average of four hours of personal care per day: 45 percent of residents have dementia diagnoses, 63 percent have bladder incontinence, 32 percent require rehabilitation, 65 percent are chair-bound, and 15 percent need respiratory treatment."

- "Nursing-home residents are extremely vulnerable to the coronavirus due to multiple comorbidities: 72 percent have hypertension, 38 percent heart disease, and 32 percent diabetes."

- "[I] n 2016, while nursing-home residents made up just 0.4 percent of the U.S. population, they accounted for 19 percent of deaths."

- "[T]he disease is easily transmitted through extensive personal care in crowded quarters from staff who travel back and forth from the wider community."

- "Unavoidably, nursing homes must interact on a regular basis with hospitals and other external medical providers."

- "And long-term care facilities have found themselves short of masks, gloves, and gowns, as protective equipment has been stockpiled for hospitals."

- "Reductions in routine visits from physicians may increase residents' underlying medical risks. Facilities must isolate and manage patients with Covid-19 who aren't hospitalized, as well as those who return and may still be infectious."

- "[T]he delayed onset of symptoms and the difficulty in identifying cases [make it hard to prevent transmission]."

- "Indeed, one study of nursing-home residents found 57 percent of those testing positive to be asymptomatic."

- "Nursing-home staff can easily become vectors for Covid19 infection. They often work in multiple facilities, share housing with those who work at other care homes, and rely on public transportation." 


\section{Clarifying "Elderly Care" and "Nosocomial"}

As we turn our focus to Stockholm, it makes sense to clarify some terms:

- Although the expression "nursing home" offers a concrete image, what we are talking about is a variety of elderly care services, so we use "elderly care."

- The focus here is on the services specifically for the elderly - hence, elderly care, not hospitals, health clinics, and other service made to the public at large.

- When we speak of "elderly care" we mean only care financed by the public-sector. In Sweden such service is often provided by private companies, but it is only service (whether public-sector or private-sector) within the publicly financed and administrated system that we speak of. Elderly people are otherwise cared for by myriad privatesector services and private individuals, but we do not speak of services outside the system.

- Infection often spreads in the service itself. The word nosocomial comes from Greek for "of the person who tends the sick." We might say: from the caregiver. But nosocomial covers also infection from interaction with others cared for. The term is not confined to hospitals. If you look up nosocomial at Wikipedia, you are taken to an entry titled: "Hospital-acquired infection." The entry begins with following sentences:

A hospital-acquired infection (HAI), also known as a nosocomial infection ...is an infection that is acquired in a hospital or other health care facility. To emphasize both hospital and nonhospital settings, it is sometimes instead called a health care-associated infection (HAI or HCAI). Such an infection can be acquired in hospital, nursing home, rehabilitation facility, outpatient clinic, diagnostic laboratory or other clinical settings.

A valuable discussion of nosocomial infection is offered by Jonathan Tepper. Nosocomial is pronounced like it looks (you can hear the pronunciation here).

\section{Sweden's Elderly Care Authorities, Institutions, and Organizations}

\section{The National Level}

\section{Public Health Agency of Sweden (PHA) (Folkhälsomyndigheten)}

The PHA is the government agency in charge of coordinating the protection of the public from outbreaks. Among its personnel is the state epidemiologist, the now-famous Anders
Tegnell. It is the PHA who provides recommendations for what the country should do.

\section{National Board of Health and Welfare (Socialstyrelsen)}

This Board oversees healthcare and social services, conducting studies, issuing recommendations and guidelines, and undertaking quality assessment. In the corona pandemic, the Board has the mission to secure protective equipment. The government has given the Board a mandate to redistribute equipment and material between regions and municipalities. The Board coordinates activities undertaken to address the crisis, notably instructions and information campaigns to personnel in municipal/regional healthcare and social services.

\section{Sweden's Municipalities and Regions (SMR) (Sveriges kommuner och regioner)}

Another actor involved in elderly care issues in Sweden is SMR, a nationwide member and employer association for all public-sector organizations municipal and regional. ${ }^{5}$ Their mission is to organize conferences and provide support to personnel involved in municipal and regional service provisions. SMR advises and assists politicians and civil servants at the municipal and regional levels. SMR does not have a formal role in dealing with the corona pandemic, but it relays needs of the municipalities and regions to the state agencies and authorities. They also provide relevant information in their capacity of employer association in relation to corona.

The Swedish government maintains an English-language website for the ordinary user of elderly care services here.

\section{The Municipal Level: Stockholm City}

Each municipality in Sweden is responsible for organizing and providing elderly care for its inhabitants. Sweden's largest municipality is Stockholm city, with 960,000 inhabitants and by far the densest population. Stockholm is exceptional in that it has an expert citywide "stewarding the elderly" organization called Äldreförvaltningen.

The most important department is the "Citywide department" (Stadsövergripande avdelningen), which is where Karlsson works. The Citywide department is responsible for Stockholm city elderly-care contracting and procurements, long-term planning of elderly housing, providing guidelines, producing policy and expert reports, and developing other strategies such as digitalization and innovation for elderly care.

\footnotetext{
${ }^{5}$ The regional (as opposed to municipal) authorities deal chiefly with hospitals and public transportation, not elderly care, so the focus here is more on municipal authorities, not regional.
} 
One of the other Stockholm city departments is Stockholm Response Service (Stockholms trygghetsjour) on call evenings, nights and week-ends for emergency help to the elderly or frail.

All of the institutional units outlined above - the PHA, the National Board, the SMR, and the Stockholm "Citywide department" - are such that their personnel do not have direct physical contact with the elderly; they are researchers, planners, administrators, and so on. ${ }^{6}$ Now we turn to those who do have direct physical contact with the elderly. Here is where the problem of nosocomial infection is central.

\section{The District Level within Stockholm City}

Finally, we reach the local level, where actual care happens. Stockholm city is divided into 14 administrative districts (stadsdelsförvaltningar). Each administrative district organizes and manages its own elderly care. The fourteen districts are shown in Fig. 3.

Elderly care in Stockholm city consists of a range of care options. Figure 4 shows how elderly care in Stockholm takes a variety of forms.

The "Other" box in Fig. 4 includes a personal-care alarm system that people over 65 can apply for. Pressing the button means immediate contact with elderly care staff and usually help within $30 \mathrm{~min}$. It also includes activity centers, escort services (ledsagare) and spouse relief services (avlösare) (Fig. 5).

The "Other" category also includes activities organized at day centers. Stockholm city lists 33 day centers, some specialized in dementia care and others a more social orientation. If needed, transport to and from the day center can be arranged. Although the activity takes place away from one's place of residence, congregating raises the issue of nosocomial infection (Fig. 6).

Another level of care is home-care services (hemtjänst). Home-care can range from cooking and cleaning to nursing care several times a day. Home-care enables one to live at home. At present, there are 178 offices of 75 different providers of home-care services in Stockholm city, 27 of the offices operated by the municipalities and 151 operated by private companies, offering care in 32 different languages (and two with Catholic orientation).

Yet another level of care is sheltered living homes (servicehus). ${ }^{7}$ There are 13 sheltered living homes; they are apartment complexes where people also have home-care service, common service, and access to a security alarm. (The sheltered living homes are not to be confused with retirement

\footnotetext{
${ }^{6}$ Stockholm City's Äldreförvaltningen also has another department (Administrativa avdelningen) which tends the internal administration of Äldreförvaltningen, so that too would not present nosocomial problems.

7 "Sheltered housing" seems to be the expression in the United Kingdom, whereas in the United States one might say "assisted living;" we've opted here for sheltered living.
}

communities offered by the private sector outside of the elderly-care system we are treating.)

Finally there are nursing homes, with round-the-clock services and care. The nursing homes are for the frailest and oldest, providing healthcare professionals onsite. In the Stockholm city system (though not in all cases within the city boundaries) there are 137 homes of this kind, 87 private, 35 public, and 15 that are publicly owned/privately operated. Of the 137 homes, 23 are "profile housing" focused on serving individuals for whom "patient" becomes apt, including those with dementia, physical difficulties, Parkinson's disease, or psychological dysfunctions.

Figure 7 shows the number of people cared for in each of the categories of elderly care. When one ponders the numbers, and the challenge of separating individuals with acute problems, often dementia, to prevent nosocomial infection, one appreciates the extreme challenges the system faces.

The other side of the nosocomial problem is the staff workers in the field. We were able to find data, for Stockholm city, for those in the public-sector only: As of December 31, 2018, there were 5387 workers employed at the district-level elderly-care services, of all types. We do not have a number for the private-sector providers. If it were equal to the public-sector (we really don't know!), that would mean upwards of 10,000 workers in Stockholm city presenting the issue of nosocomial infection.

An additional dimension from the worker side is that elderly care is labor intensive with many jobs requiring only high school education. The work is quite low-pay and has a relatively low status. As a consequence, it is a labor market where immigrants often start their careers. As a matter of fact, working in elderly care is the most common job among refugees in Sweden, even ahead of restaurant work or cleaning, with $12.1 \%$ of refugees reporting that their first job in Sweden was in elderly care (Vennberg and Videnord 2019, 112). Meanwhile, we know that immigrants have been disproportionately hit by Covid19. ${ }^{8}$

\section{A Shocking but Potentially Misleading Ratio}

Using data from the Board of Health and Welfare, we calculated two percentages, and then compared those, arriving at a rather shocking ratio. The analysis is for Stockholm city. First, we consider the population of all those who are aged 70 or over and either in nursing homes or receiving home-care. As of December 31, 2018, there were 18,169. Meanwhile, as of May 14, 2020 there were 357 nursing-home Covid deaths and 180 home-care Covid deaths, making a total of 537. Thus we estimate that the portion of those in elderly care who had been recorded as a Covid death as of May 14, 2020 as 3.0\%.

\footnotetext{
$\overline{{ }^{8} \text { On immigrant }}$ populations in Stockholm showing disproportionately high Covid incidence, see here.
} 
Fig. 3 The fourteen districts within Stockholm city. (Image source)

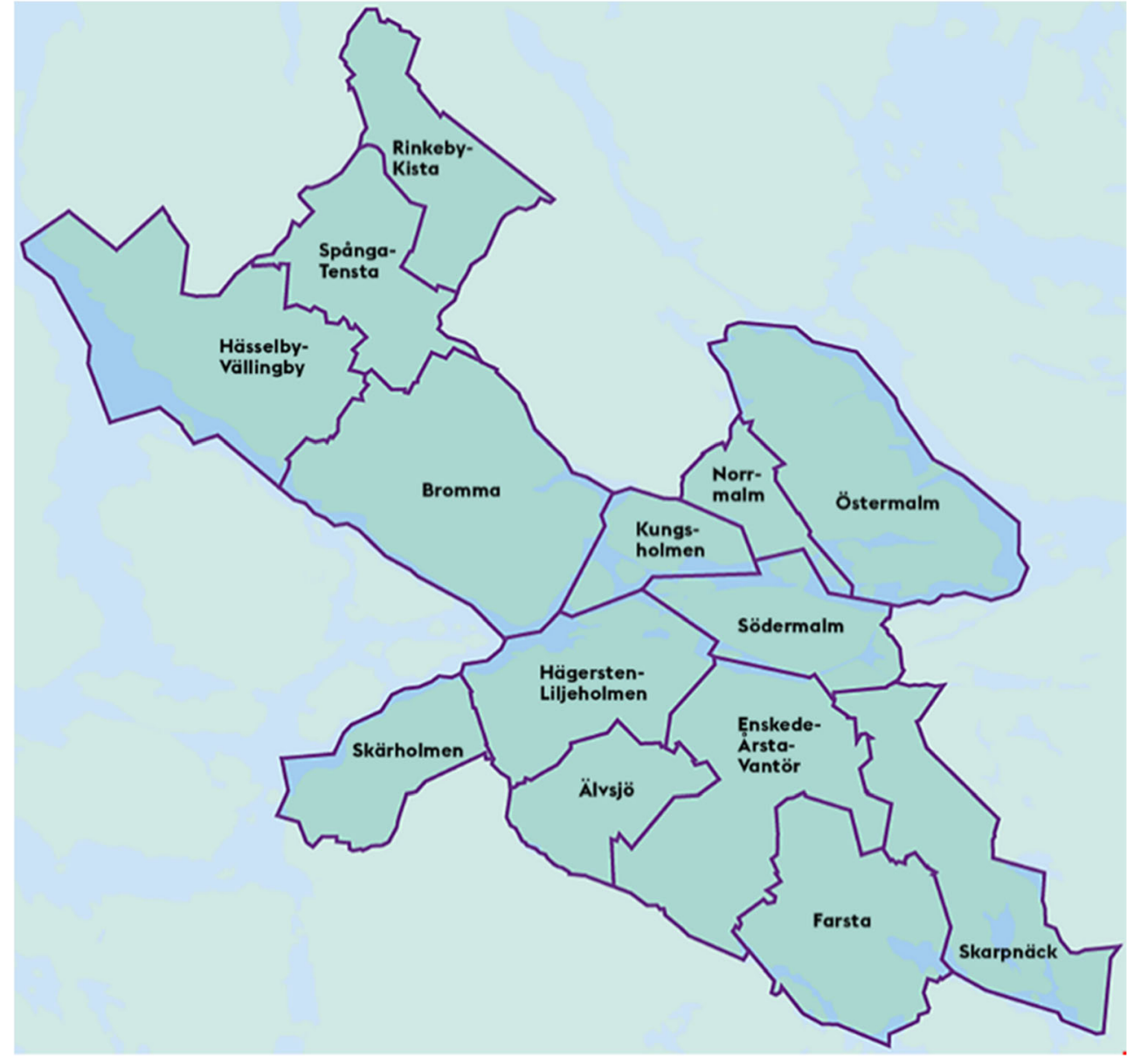

Now, consider the population of all those who are aged 70 or over and not in nursing homes nor receiving home-care. As of December 31, 2018, there were 82,551. Meanwhile, as of May 14, 2020 there were 121 Covid deaths of people who had had neither sort of elderly care. Thus we may estimate that the portion of those $70+$ without elderly care who had been recorded as a Covid death as of May 14, 2020 as $0.15 \%$.

When we compare the first percentage to the second, we get a ratio of 20 to 1 . That is, people aged 70 and over who had had elderly care were about ${ }^{9} 20$ times more likely to have died than those without elderly care. But it does not mean that elderly services have been killing people. The set of people who are granted elderly care services is very different from the set of people who do not receive services. That is especially true for those in the nursing homes, where mortality has been higher. ${ }^{10}$ The risk of dying from Covid-19 increases with age and the probability that you have elderly care increases with

\footnotetext{
${ }^{9}$ There are forms of elderly care aside from nursing homes and home-care (such as the trigger alarm, the day-centers, the sheltered living homes, and so on); however most people receiving such other services would also be receiving home-care, so this 20 to 1 ratio is probably close to reality.

${ }^{10}$ As of May 14, 2020 the National board reported 357 individuals dead by Covid-19 in nursing homes, of 5268 living in nursing homes (as reported in the Elderly care in Stockholm time-series) making 6.8\%. For home-care the numbers are 180 dead by Covid-19, of 12,901 receiving home-care, or $1.4 \%$.
}

age. The correlation between elderly care and Covid19 death stems from the same broad cause: underlying health fragility. Figure 8 shows how receiving elderly care rises with age.

Data on the years 2015 and 2016 show that among those with bodily ailments (somatiska), as opposed to for example dementia, from the day such person enters a nursing home the median length of the remainder of their life is 9 months; the median for all entering nursing homes is 16 months (Sweco 2019, 45). Most Covid19 victims had already been in the nursing home for some time. The disease tends to strike down the most vulnerable, and the disease takes some time. From all considerations, it is reasonable to say that those who died of

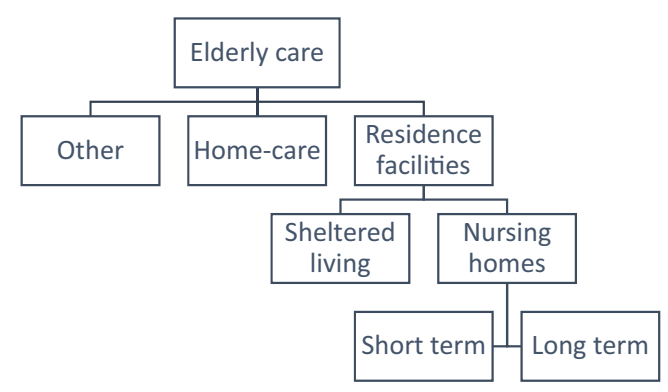

Fig. 4 Types of elderly care in Stockholm city 


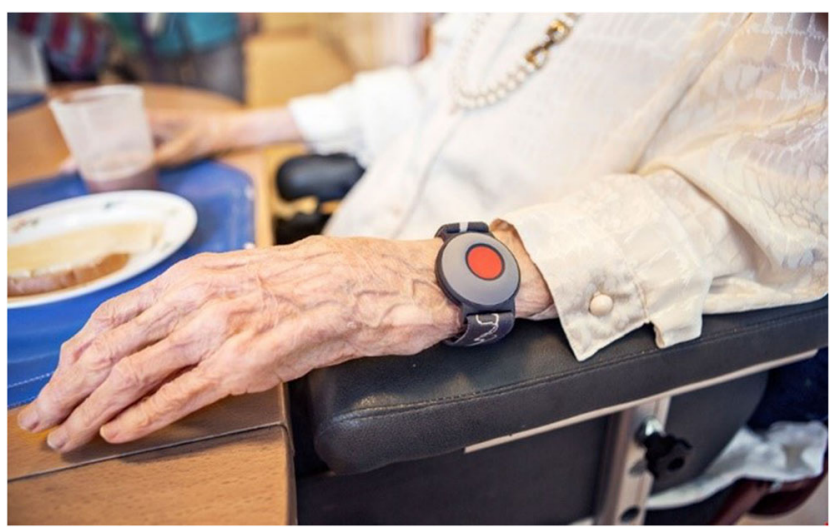

Fig. 5 Trigger alarm service provided by Stockholm's elderly care system. (Photo source)

Covid19 in Stockholm's nursing homes had a life-remaining median somewhere in the range of 5 to 9 months.

Also, the Covid19 death toll has been much more extreme in the nursing homes as opposed to those receiving home-care. Using an approximately corresponding breakdown of the two populations in either sort, we calculate $357 / 5047=7.1 \%$ of nursing home residents dying of Covid19, and 180/13886= $1.3 \%$ of home-care recipients dying of Covid $19 .{ }^{11}$ The fivefold difference between the two rates reflects both that the nursing home residents are much more vulnerable and that the nosocomial problem is more extreme there.

The overall number of deaths of people in nursing homes in Sweden has not, in fact, been much elevated, compared to recent years. Over the period January through April 2020, the number of deaths among those in nursing homes was about 11,000 , whereas for the previous year it was about 10,000 . And that previous year was unusually low, partly because the 2019 flu season was relatively mild. It is possible that come 2020 the nursing-home population was even more vulnerable than usual.

\section{Barbro Karlsson on Stockholm City's Elderly Care and Covid19}

The dialogue between Karlsson and Stern presented here has been fashioned for the purposes of this article and rendered into English. But the present text has been approved by Karlsson, as representing her knowledge and sentiment faithfully and accurately. Footnotes and bracketed insertions within the interview are our own, not Karlsson's.

\footnotetext{
${ }^{11}$ The numerators of those two percentages come from the first paragraph of this subsection, while the denominators come from Stockholm City 2020. Note that the denominator for the nursing homes is actually the number of places (which are essentially always filled), not the number of residents served over the approximately two months during which the Covid19 deaths occurred, which would be somewhat more than 5047 . Thus the $7.1 \%$ is a bit of an overstatement of the nursing-home death rate.
}

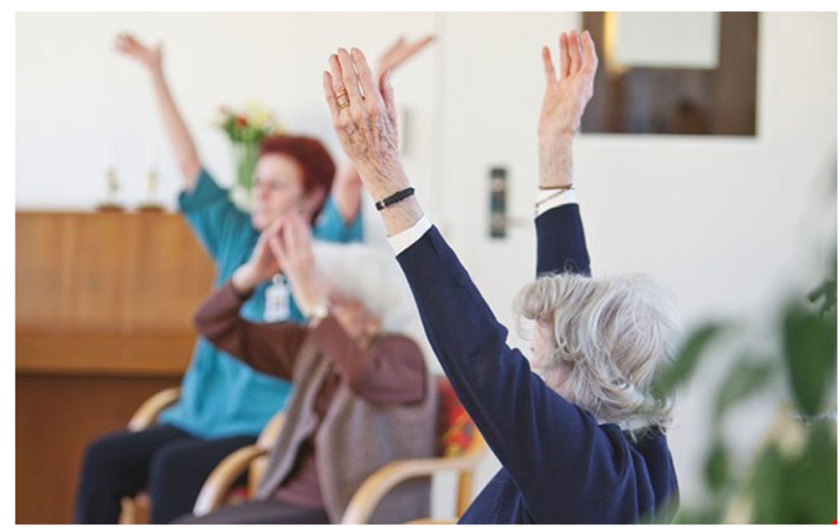

Fig. 6 Day center activity in Stockholm. (Photo source)

Stern: The press and media in Sweden and YouTube material by Giesecke and others seem to be leaving people with the impression that Stockholm elderly care has failed terribly in protecting the elderly. What is your view?

Karlsson: The Public Health Agency (PHA) does indeed give that impression. They have not actually pointed a finger at us, in elderly care, but when they say "We've failed in the elderly care sector" that is the impression people get. People hear them saying: "We've done nothing wrong. It is elderly care providers in Stockholm and elsewhere who have failed to protect the elderly."

Stern: So, are you angry at the PHA?

Karlsson: I wish they'd done more to say that "we" is the entire system. And they are at the top of that system. The picture people get is that of the elderly-care services being incompetent, indifferent, or lacking necessary means to protect their workers and their beneficiaries. And not just the PHA. Also the prime minister and the minister of social affairs have allowed the impression of elderly care being in a state of chaos, with low quality care and staff that does not do a proper job of protecting

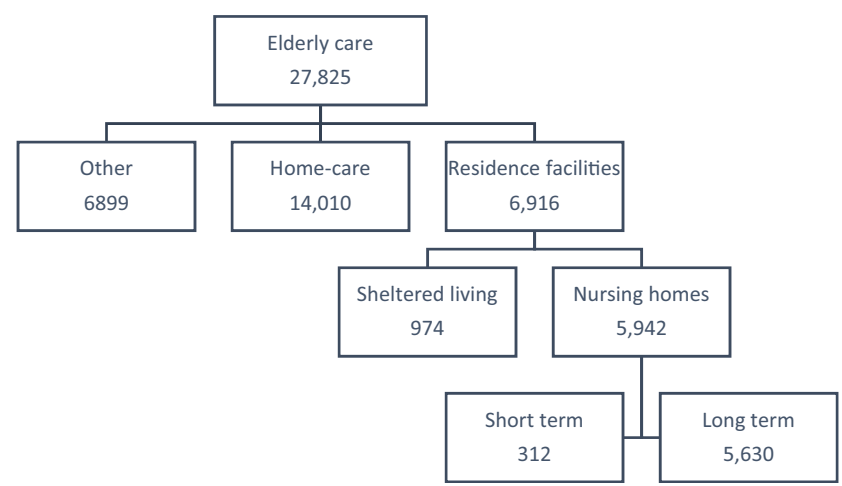

Fig. 7 Types of elderly care and number cared for in Stockholm city. Source: Äldreomsorg tidsserier 
E Percentage of age group receiving elderly care (nursing homes or home-care)

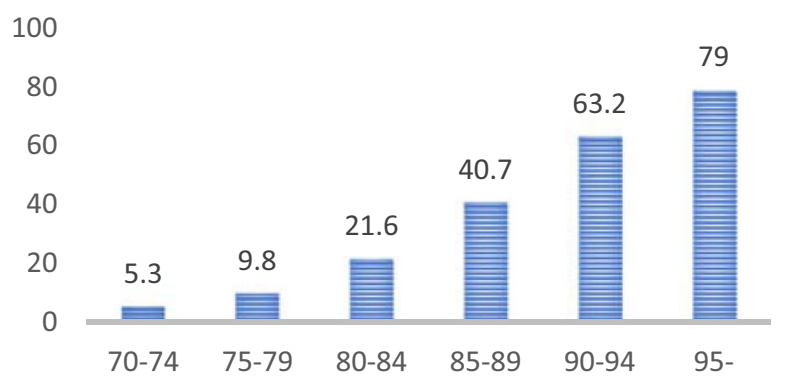

Fig. 8 Percentage of age group in Stockholm city receiving elderly care. Sources: Computed by population numbers from Statistics yearbook for Stockholm 2020 and elderly-care numbers from Elderly care in Stockholm time-series.

the individuals under their care. Those impressions are wrong.

Stern: Has elderly care not made mistakes? Been slow to make adjustments?

Karlsson: Of course there have been mistakes but this was a most unusual situation. First of all, Covid19 was declared a public social infection on March 10, 2020. It is important to understand that elderly care units are part of society and will have their share of contagious individuals coming in and going out. They are after all open day and night, every day of the week, every week of the year. Hundreds of people go to work in these homes every day. Although safety measures were taken, the virus is particularly tricky since people without symptoms can be contagious, and it seems people testing negative can turn out to be sick. Also, the positive tests seem not to be conclusive. Preventing outbreaks is near impossible in such a situation. Once a resident in one the homes is infected, it is likely to spread to some of the other vulnerable residents, since they are companions to one another. They normally would eat together, hang out, talking, watching television. Companionship is crucial to someone in their condition. In such a setting the disease will naturally pass rapidly from one resident to a next. However, things have changed, of course, and nursing homes now enforce distancing even when eating their meals.

Stern: Of course, but could one not have implemented stricter rules to start with?

Karlsson: The really frustrating thing in this whole media confusion is that people don't realize that, while the municipalities and regions make final decisions for the care within their own systems, there is a strong norm of following the lead of the PHA. So now, it is unfair for people to say that the initiation of changes and adjustments should have come from the local players.
Changes and adjustments are usually carefully discussed and assessed by PHA and the other state agencies [such as the National Board and the MSR, discussed above]. Their approval carries great weight. Now, everyone expects us to be the source of quick changes.

Stern: So, what happened in February and early March? Karlsson: Stockholm city has followed PHA strictly from day one. For instance, it took several weeks before the PHA declared a stop of visitation. The Stockholm municipal homes had implemented visitation stops two weeks prior. And some privately run homes in the system were even earlier to shutdown visitors. Stockholm elderly care facilities overall have done what they could during the outbreak. It is important to note that residence homes are people's homes. Forbidding them from seeing their family and loved ones in their own homes is not a decision to be taken lightly. Panicked reactions are often not the most well considered reactions and making decisions during a crisis is hard. The situation has been unfolding and the uncertainty extreme! It's easy to say afterward that this-and-this should have been done. But the system has never been quick and nimble. I have been immersed in the crisis since day one and think we've done a pretty good job under the circumstances.

Stern: How about protective equipment?

Karlsson: In the beginning of the crisis, there was a shortage of protective equipment but not really any more [said on 10 May 2020]. Today we are in a good position to follow the guidelines as set up by the PHA. The difficulty now is the conflicting information about protective devices coming from elsewhere, increasing the worry of staff and the elderly. And it does not help that the PHA itself suddenly changes its recommendations, as they did recently regarding the use of face masks. ${ }^{12}$ When Tegnell then says "it is up to the municipalities" he seems to be avoiding possible blame and leaving it to the municipalities to take over responsibilities. The municipalities are accustomed to PHA guidance and are worried that PHA will disapprove of what they do. When that is what everyone is used to, it becomes a problem when the recommendations from PHA are fuzzy. In the end, Stockholm city decided to stick with using a face visor and did not mandate face masks. Stern: Could one not have implemented a reform where basically all staff and patients were locked-down for two weeks?

Karlsson: In retrospect such a policy may seem viable but remember: crises management is unfolding over time. We have lately implemented reforms that, in the

\footnotetext{
$\overline{12}$ There had been a controversy over mandating face masks in elderly care, see Swedish reporting here.
} 
early days of Covid I thought were unthinkable. Maybe someone will say that we all should have been ready to hold hands and jump into action to get behind such extreme measures, but it just seemed impossible. For instance, we have implemented a policy where we move dementia patients with Covid, but otherwise healthy, into specific short-term homes, because they would not understand confinement. If someone had told me two months ago that we will be forcing old people out of their homes, I would have laughed. But here we are. Stern: So, in your opinion, what are some of the reasons we see such high mortality among the elderly care facilities in Stockholm city - is it not incompetence at least partly? Karlsson: You have to realize that our residents in elderly care are generally less healthy than those in Finland and Denmark. Stockholm does more homecare. Swedish seniors have the opportunity to stay in their own [private] homes for much longer because of the care workers that help them manage in their homes [home-care]. Hence the people who do enter nursing homes are those with very extensive needs. The average age is 85 and many have multiple illness or longstanding dementia.

Stern: So, your saying that Stockholm's nursing homes really have concentrations of the most vulnerable.

Karlsson: Yes.

Stern: There is talk that one reason Sweden has had a worse toll than our Nordic neighbors is that we have larger nursing homes, making infection more likely with more workers going in and out, and then spreading to a larger group of elderly in the home. Is size of nursing homes a partial explanation for a higher death toll?

Karlsson: I cannot speak to the situation elsewhere. Within Stockholm city, we have care homes with accommodation ranging from 12 to 239 places. The majority of homes have between 50 and 60 places (54 is almost a rule in cases where a completely new housing is built). I have seen no indication that housing with more places have been harder hit. Regardless of how many places an accommodation has in total, all the accommodation is divided into departments of about 9 places each and most of the staff work solely within their department. The only people moving all over the house are nurses and paramedics, and in some cases night staff. Stern: How have those receiving home-care responded now with the onset of Covid?

Karlsson: Now, seniors who can manage mostly by themselves have tended to discontinue home-care. That alone could be dangerous, because they might need the help to prepare their food, keep up hygiene, get fresh-air, sunlight, exercise, and so on. Also, if a needy person discontinues home-care and is married, then the spouse, who is also elderly, is often overstrained doing the things that home-care used to do. For the seniors who continue with home-care, they will continue to be at some risk of Covid exposure but of course precautions have evolved quickly.

Stern: Do you think Stockholm in representative of Sweden generally?

Karlsson: Not really: Stockholm with its high density of population makes it even more likely that you can stay at home for longer. The main thing, though, is ability of the service providers. In the city one home-care worker can get from home to home quickly and therefore service many people in one day. If you live in remote places it may be impossible to stay at home when you can't take care of yourself and drive to the store, and people are too spread out to have thick home-care services. So there will be differences also within Sweden in how long and how sick you typically are when you move into a nursing home.

Stern: What happens then, when someone who is staying at home gets Covid?

Karlsson: We have special teams that work with patients who are fit enough to remain in their own home. You've got to remember that even seniors and people who need help to manage their everyday life sometimes do not get that sick from Covid. And if they do, they go to the hospital like everyone else.

Stern: Are they very fearful of getting Covid?

Karlsson: Yes, and perhaps too fearful. In fact data now indicate that less than $1 \%$ of home-care recipients currently have Covid. ${ }^{13}$ Also, remember, there are hundreds of old people who are recovering from Covid. From the news reporting one would think that it is a death sentence to get the disease but that is clearly not our finding in home-care and nursing homes. Especially among dementia patients who physically are often quite healthy, there are many examples of mild symptom Covid.

Stern: So when researchers like Karin Ekström and Johan Löfqvist claim that the quality of elderly care is quite bad, they are wrong?

Karlsson: Yes, in my assessment, suggestions about "the good old days" of Sweden's elderly care are wrong. I have been working in the elderly care sector for 30 years, and it has never been better. The reforms implemented in 1992 have given seniors home-care so they get to stay in their homes for much longer with assistance and nursing homes have become a real home for the elderly and not an institutional existence. Prior to the reform it was common that elders lived in impersonal wards with many beds to a room. Now everyone has his or her own room, with personalized furniture, if not a personal apartment in the nursing home. The

\footnotetext{
${ }^{13}$ Stockholms City 2020.
} 
Fig. 9 Where the individual died (of all Covid19 deceased in Sweden). Source: Socialstyrelsen. Image source

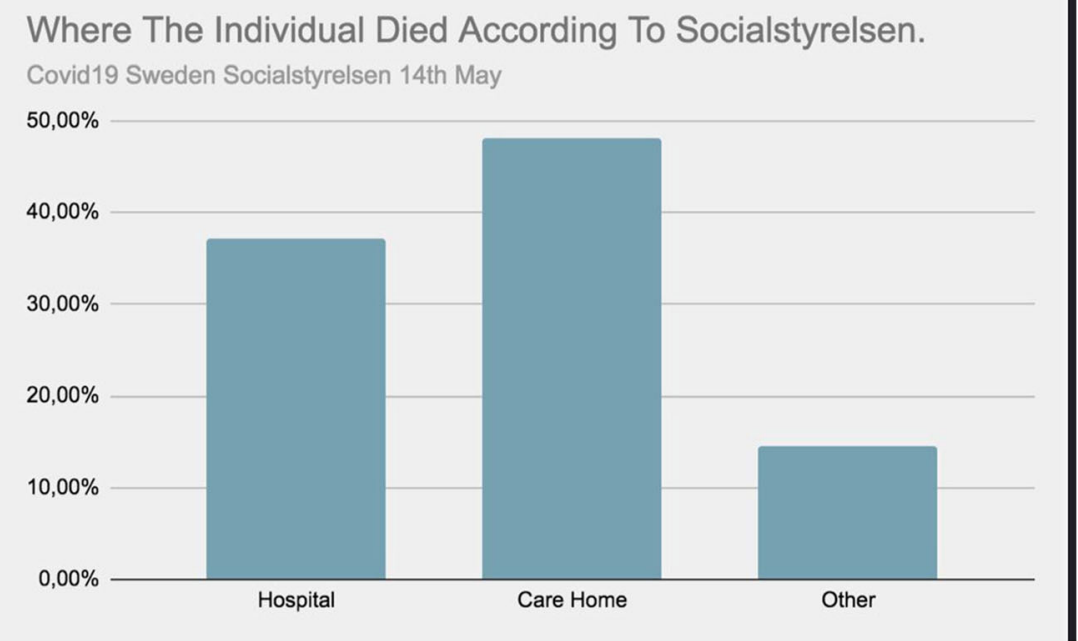

elderly care today is much more humane and dignified than it used to be.

Stern: So if home-care workers are not a big factor in spreading the disease, infection is passed around in the Stockholm system by all the interaction within the system. Is that why Stockholm is so extreme because the system is so build-up there?

Karlsson: Here's another reason for why the death rates might be higher in Stockholm than in the rest of Sweden or even the rest of the world. People stay at home longer, and when they get into a nursing home they are quite fragile. Once one is admitted into an elderly home one usually has less than a year of life ahead, for those with chronic illnesses. [See above for estimated range of liferemaining median of 5 to 9 months for the nursing-home Covid19 deceased.].

Stern: But how about this: There has been quite a lot of worries about the sick in elderly care homes dying from suffocation during horrible sufferings. What do you say to that?

Karlsson: Well, the PKC [Palliativt kunskapscentrum] has studied the matter. In what is called the palliative register [palliativregistret], information of all deaths are collected. It turns out that most patients with Covid who stay in elderly care typically die during calm and nonsuffering circumstances [see here]. You have to realize that not everyone who dies from Covid gets to the worst stages, when the lungs aren't operating. The virus multiplies and creates fever, and frail people might pass away then, before distress in the lungs. We see that they get very tired, and most patients do not live long enough to get to the phase where there are breathing difficulties and the anxiety related to that. [See Fig. 9].
Stern: The picture I get is that the oldest and frailest often don't have the strength to get to the worst stages of struggle against the disease.

Karlsson: The point is that that is the case for many of those in the nursing homes who have succumbed to Covid. But I should add that a large of nursing home residents recover from Covid19. Sometimes they quietly pass away, but sometimes they quietly recover, without ever entering the severe stages of the disease.

Stern: One thing I have been thinking of is that the Swedish way of distributing and decentralization of power, say between the SKR, PHA, and each municipality may not be the best way to deal with a crisis. Would it have been better to centralize and make one player responsible for the whole?

Karlsson: In my experience, and I do think research supports this, large and centralized organizations are slow to adjust. Thinking that such a structure would be better at dealing with a crisis does not make sense to me. On the contrary, I think such a structure would have been slow to respond and that would have made the situation even worse.

Stern: There has been some in the news saying that the reason elderly care homes failed to keep the pandemic outside is that there are so many private home-care providers, with lots of temporary staff, lower levels of education among their staff etc. Can you comment on that? Karlsson: Indeed, all along Stockholm city has claimed that the issues of ownership is completely uninteresting in this case. We see no differences between public and private providers. ${ }^{14}$ If anything, with regard to quality, our surveys of quality of elderly care indicate year after

\footnotetext{
${ }^{14}$ An internal document of Stockholm city, where Karlsson works, reports that as of May 5, 2020, both private-sector and public-sector had rates 0.6 to $0.7 \%$ Covid19 cases among home-care recipients and $6.4 \%$ among nursing home residents (Stockholm City 2020).
} 
year that private providers come out ahead of the publicsector managed care. On average, private providers have slightly less temporary staff and higher education levels among their staff.

Stern: So, now, what is the situation in Stockholm's elderly care?

Karlsson: It seems [May 20, 2020] that the worst is behind us, but we cannot know for sure. We can say that things in Stockholm's elderly care have been improving steadily, even rapidly, in terms of new cases of Covid.

\section{Conclusions}

Experiences across cities, states, and countries will need to be learned and compared to figure out what strategies in elderly care work in fighting Covid19. Our chief goal in this article has been to explain the experience in Stockholm, so that people can learn from it worldwide.

Death rates have been much higher in Sweden than in and the other Nordic countries, and, at this time, remain highly unclear in causation. Factors to consider are differences in concentration of the most vulnerable in nursing homes (touched on in this article), lockdown strategy, immigrant transmission in elderly care, metro ridership (Stockholm's is about four times that of Copenhagen's), and globetrotting back from the Continent (perhaps from internationalized business, immigrant travel, skiing during the February vacation, and so on). And then there are protocol, procedural, and administrative matters in elderly care, some of which have been touched on in this article. One notable issue is that Sweden is said to have been too ready to settle for so-called palliative care in the nursing homes, that is, too reluctant to send serious Covid19 patients in nursing homes on to hospitals and intensive care (Pancevski 2020, Neuding 2020). ${ }^{15}$ If that is so, it raises questions as to where to place blame: The candidates would include the National Board (Socialstyrelsen) for its guidelines on the matter, the elderly care system (both the providers and the administrators), particularly associated doctors who may have misinterpreted guidelines, and the hospitals and intensive care units, who may been less favorable to receiving Covid19 patients than they should have been. Investigations and heated discussion in Sweden unfold as we go to press.

But to get perspective, elderly care services need to be seen from the inside. Whatever the particular errors to be identified, elderly care is an inevitable battleground in the war against Covid19, most notably because the most vulnerable are collected there. That battle calls for guerilla warfare by those with

\footnotetext{
${ }^{15}$ We are grateful to Benny Carlson for pressing the issue with us.
}

contact with them. The great challenge is to maintain both companionship and the care itself-oftenhigh-touchcarewithout transmitting the disease to the vulnerable. The setting and practice of elderly care give rise to nosocomial infections, from care-givers and from others cared for. The challenge is not special to Stockholm; it is worldwide. The problem calls for targeted solutions by those close to the vulnerable individuals.

\section{Appendix}

Folder containing Excel files with computations used in this study. Link

\section{References}

Coletta, Amanda. 2020. Canada's Nursing Home Crisis: 81 Percent of Coronavirus Deaths Are in Long-term Care Facilities. Washington Post, May 19. https://www.washingtonpost.com/world/the americas/coronavirus-canada-long-term-care-nursing-homes/2020/ 05/18/01494ad4-947f-11ea-87a3-22d324235636 story.html

Ekström, Karin M. and Johan Löfqvist. 2020. Coronakrisen synliggör ovärdig syn på ålderdom. Dagens Nyheter, May 6. https://www. dn.se/debatt/coronakrisen-synliggor-ovardig-syn-pa-alderdom/

Folkhälsomyndigheten. 2020a. https://experience.arcgis.com/experience/ 09f821667ce64bf7be6f9f87457ed9aa

Folkhälsomyndigheten. 2020b. Bekräftade fall i Sverige - daglig uppdatering. https://www.folkhalsomyndigheten.se/smittskyddberedskap/utbrott/aktuella-utbrott/covid-19/bekraftade-fall-isverige/

International Long-term Care Policy Network. 2020. International Reports on COVID-19 and Long-Term Care. https://tccovid.org/ international-reports-on-covid-19-and-long-term-care/

Neuding, Pauina. 2020. När Cynismen Görs till Verklighetsbeskrivning, Svenska Dagbladet, June 11. https://www.svd.se/nar-cynismengors-till-verklighetsbeskrivning

Palliativt Kunskapscentrum i Stockholms Län. 2020. Nyhetsbrev, April 27. https://public.paloma.se/webversion?cid $=2446 \& \mathrm{mid}=$ $617929 \&$ email key=00000000-0000-0000-0000$000000000000 \&$ languageCode $=\mathrm{sv}$

Pancevski, Bojan. 2020. Coronavirus Is Taking a High Toll on Sweden's Elderly. Families Blame the Government. Wall Street Journal, June 18.

Pope, Chris. 2020. The Real Center of the Pandemic: Saving Nursing Homes from Covid-19. City Journal, May 10. https://www.cityjournal.org/coronavirus-super-spreaders-nursing-homes

Reynolds, Emma. 2020. Sweden Says Its Coronavirus Approach Has Worked. The Numbers Suggest a Different Story. CNN, April 29. https://edition.cnn.com/2020/04/28/europe/sweden-coronaviruslockdown-strategy-intl/index.html

Rothschild, Nathalie. 2020. The Hidden Flaw in Sweden's AntiLockdown Strategy. Foreign Policy, April 21. https:// foreignpolicy.com/2020/04/21/sweden-coronavirus-anti-lockdownimmigrants/

Socialstyrelsen. 2020a. https://www.socialstyrelsen.se/

Socialstyrelsen. 2020b. Information i Dödsorsaksintyg - Förtydligande Vägledning till Läkare Som Utfärdar Dödsorsaksintyg. April 20. https://www.socialstyrelsen.se/globalassets/sharepoint-dokument/ dokument-webb/ovrigt/information-till-dodsorsaksintyg-lakarecovid19.pdf 
Socialstyrelsen. 2020c. Statistik över Antal Avlidna i Covid-19. https:// www.socialstyrelsen.se/statistik-och-data/statistik/statistik-omcovid-19/statistik-over-antal-avlidna-i-covid-19/

Socialstyrelsen. 2020d. Dödsorsaksintyg Över Avlidna i Covid-19 Visar Högst Andel i Stockholm. https://www.socialstyrelsen.se/omsocialstyrelsen/pressrum/press/dodsorsaksintyg-over-avlidna-icovid-19-visar-hogst-andel-i-stockholm/

Stockholm City. 2020a. Sammanställning av Uppgifter om Antalet Personer med COVID-19 per Regiform.

Stockholm City. 2020b. Elderly care services in the City of Stockholm. https://aldreomsorg.stockholm/other-languages/elderly-careservices/

Stockholm City. 2020c. Statistisk Årsbok. https://start.stockholm/omstockholms-stad/utredningar-statistik-och-fakta/statistik/statistiskarsbok/

Svenska Palliativ Registret. 2020. https://palliativregistret.se/fou/fou-inenglish/

Sweco. 2019. Äldreomsorgsprognos 2019. Framskrivning av Äldreomsorgsbehovet Perioden 2020-2040. Stockholm.

Sydsvenskan. 2020. Liknande Dödstal på Äldreboenden Varje År. May 23. https://www.sydsvenskan.se/2020-05-23/liknandedodstal-pa-aldreboenden-varje-ar

Tepper, Jonathan. 2020. Ground Zero: When the Cure Is Worse than the Disease.Medium, April 13. https://medium.com/@tepper_jonathan/ ground-zero-when-the-cure-is-worse-than-the-disease$3 \mathrm{c} 513 \mathrm{~d} 91393 \mathrm{~d}$

Unherd TV. 2020. Why Lockdowns Are the Wrong Policy: Swedish Expert Prof. Johan Giesecke. April 17. https://www.youtube.com/ watch? $=$ bfN2JWifLCY\&t=976s
Wennberg, Karl and Emilie Videnord. 2019. Flyktingars Arbetsmarknadsintegration i Sverige. Chapter 6: 103-122 in En dynamisk arbetsmarknad(ed) Lotta Stern. Stockholm: Dialogos förlag.

Yap, Han Lin. 2020. Coronavirus in Sweden. https://platz.se/ coronavirus/?lang=en

Publisher's Note Springer Nature remains neutral with regard to jurisdictional claims in published maps and institutional affiliations.

Charlotta Stern Advisory Editor of Society, is Professor of Sociology at Stockholm University and Deputy Director of the Ratio Institute in Stockholm.

Daniel Klein Advisory Editor of Society, is Professor of Economics and JIN Chair at the Mercatus Center at George Mason University, and Research Fellow at the Ratio Institute. The authors are especially grateful to Barbro Karlsson for guiding our understanding and responding meticulously on multiple drafts. For valuable feedback, we also thank Lyle Albaugh, Benny Carlson, Warren Lammert, and Jon Murphy.

Daniel Klein is professor of economics and JIN Chair at the Mercatus Center at George Mason University, and research fellow at the Ratio Institute (Stockholm) 